\title{
Credit Risk Analysis and Evaluation of Internet Supply Chain Finance Listed Companies -- Based on Structural Entropy Weight TOPSIS Method
}

\author{
Xudong Cai ${ }^{1, *}$ Hongmei Zhang ${ }^{2}$ \\ ${ }^{1}$ School of big data application and economics, Guizhou University of Finance and Economics \\ ${ }^{2}$ School of big data application and economics, Guizhou University of Finance and Economics \\ *Xudong Cai.1807647512@qq.com
}

\begin{abstract}
The emergence of supply chain finance has effectively solved the problem of financing difficulty and high cost for small and medium-sized enterprises. The rapid development of the Internet has magnified this advantage. However, based on its diversified main body and complex business process, the risk of Internet supply chain is also increasing, resulting in economic instability and hindering economic development. Scientific and reasonable analysis of Internet supply chain financial credit risk is of great significance to promote the development of supply chain finance and expand financial services. In view of the limitation of single evaluation method and imperfect index system, this paper introduces Baidu search index and stock bar comprehensive score to construct the credit risk evaluation system of Internet supply chain finance from six aspects: operation ability, debt paying ability, profitability, development potential, mortgage factor and condition factor. It also selects 24 Internet supply chain finance related companies in 2019 The empirical results show that: profitability, operating capacity, solvency can provide strong explanatory power, and Structural Entropy TOPSIS method can analyze the credit risk of these enterprises to a certain extent.
\end{abstract}

Keywords: Internet supply chain finance, Credit risk, Index system, Entropy weight method, TOPSIS method

\section{互联网供应链金融上市公司信用风险分析与评价 -一基于结构熵权-TOPSIS 法}

蔡旭东 ${ }^{1,}{ }^{*}$ 张红梅 $^{2}$

\footnotetext{
${ }^{1}$ 贵州财经大学大数据应用与经济学院

2贵州财经大学大数据应用与经济学院

*蔡旭东. $1807647512 @ q q . c 0 m$
}

\section{摘要}

供应链金融的出现，有效的解决了中小企业融资难、融资贵的问题，互联网的快速发展更是放大了这一优势， 然而，互联网供应链基于其多元化的主体和复杂的业务流程其风险也在加剧，从而造成经济的不稳定、阻碍经 
济的发展。科学合理的分析互联网供应链金融信用风险, 对于推动供应链金融的发展, 拓展金融服务有着重要 的意义。文章针对已有评价方法单一和指标体系不完善的局限性，引入百度搜索指数和股吧综合评分，从营运 能力、偿债能力、盈利能力、发展潜力、抵押因素、条件因素六个方面构建互联网供应链金融信用风险评价体 系: 并选取了 2019 年度跟互联网供应链金融相关的 24 家上市公司的指标数据, 实证结果表明: 盈利能力、营 运能力、偿债能力能提供较强的解释力, 结构摘权-TOPSIS 法能够在一定程度上分析这类企业的信用风险。

关键词：互联网供应链金融，信用风险，指标体系，熵权法，TOPSIS 法

\section{1. 引言}

自 2019 年中国银保监会发布了《关于推动供应 链金融服务实体经济的指导意见以来》供应链金融得 到了快速发展, 随着云计算、大数据等数字化技术的 发展, 互联网技术正逐步渗透到供应链金融之中, 于 是互联网供应链金融应运而生, 为中小企业提供了全 方位、更便捷的服务，促进了中小企业的发展，基于 不同的运作模式可以将其划分为 B2B 电商平台、支付 +金融、ERP 系统、供应链管理平台、SAAS 模式、物 流+电商服务平台等。正是由于其多元化的主体结构、 复杂的业务流程, 导致了信用风险事件频发, 对经济 造成了一定的冲击。随着越来越多的金融机构、中小 企业、互联网公司集结于供应链, 信用状况会因为联 结而放大。因此, 建立符合互联网供应链金融特征的 信用风险评价体系和评价方法, 对于控制互联网供应 链金融的信用风险具有重要的战略意义和现实意义, 是互联网供应链金融能否稳定快速发展的关键。

对互联网供应链金融下企业的信用风险进行科 学合理的评价是加快互联网供应链金融的发展和提 高企业竞争力的关键一步。截止目前, 关于供应链金 融的信用风险评价大多是基于 $5 \mathrm{C}$ 信用理论建立的风 险评价体系。许贵义 (2016) ${ }^{[1]}$ 基于 S 汽车锁业公司 的案例, 根据信用 $5 \mathrm{C}$ 评价理论, 确定品德、资本、能 力、抵押、条件作为评价供应链金融下中小企业信用 风险的一级指标。肖瑾 (2018) ${ }^{[2]}$ 依据影响因素分析、 指标构建原则的逻辑构建了包括应收账款特征、质押 物特征、合作信用度、核心企业信用度等在内的共计 8 个指标来衡量中小企业的信用风险。刘兢轶、王聝 婧、王静思 (2019) ${ }^{[3]}$ 基于制造业中小企业样本进行 分析，通过因子分析提取了包括核心企业信用状况、 盈利能力、营运能力、增长速度、偿债能力在内的五
个主因子, 之后又通过 Logistic 模型回归剔除了增长 速度和盈利能力因子。袁双龙 (2019) ${ }^{[4]}$ 从品德、资 本、能力三个方面对信用风险进行了分析并基于整体 性、实用性、定性定量相结合的原则构建了企业历史 信用度、营运能力、质押物特征等共计 7 个指标进行 风险评价。熊莉 (2019) ${ }^{[5]}$ 从供应链的稳定性和行业 发展情况两个方面分析信用风险, 设计了申请人资 质、交易对手资质、融资项的资产状况、供应链运营 状况四个指标。韩琴（2019） ${ }^{[6]}$ 在研究了供应链金融 的主要融资模式后, 构建了宏观经济环境、企业基本 素质、核心企业历史信用度、供应链关系强度四个一 级指标。张俊材, 徐超毅 (2019) ${ }^{[7]}$ 以钢铁行业为研 究对象, 依据实用综合性原则构建了诸如公司融资结 构、融资规模、贷款额度、资金利用率等共计 15 个 指标。匡海波、杜浩、丰吴月（2020） ${ }^{[8]}$ 基于金融街 普遍认可的 “ $5 \mathrm{C}$ 原则” 综合研究核心企业和上下游 企业的整体风险，建立了包括申请企业资质、交易企 业资质、资产状况、运营情况在内的四个一级指标, 盈利能力、质物特征等 14 个二级指标。至于评价方 法方面, 大多数学者基于 Logistic 二元回归、KMV 模型、Credit Metrics 模型、Credit Portfolio Risk 模型、 模糊语言进行信用风险分析。Bin Zhu, Zeshui Xu （2016） ${ }^{[9]}$ 回顾了 2010 年至 2016 年在国际学术期刊 上发表的关于犹豫模糊集的解释、建模和应用的主要 相关论文。并提出了今后可能的研究方向。李杰辉、 陈珊珊 (2020) ${ }^{[10]}$ 以房地产上市公司为例采用 Logistic 二元回归模型预测企业的守约程度，文章选取了 41 个样本企业, 模型准确率达到了 $73.17 \%$ 提供了一定 的解释力。赵欢 (2020) ${ }^{[11]}$ 着眼于农副行业产品, 运 用 Logistic 二元回归模型进行了实证分析, 模型准确 率高达 $92.3 \%$, 准确性相比于传统模型较高。邓伟 
（2020） ${ }^{[12]}$ 选取了制造业的 30 家 ST 与非 ST 企业利 用基于期权理论的 KMV 模型进行违约概率分析, 实 证发现 ST 企业和非 ST 企业的违约距离和预期违约概 率差异较为显著。张天宇 (2020) ${ }^{[13]}$ 基于 KMV 模型 对上市中小企业公司进行了违约概率评价, 以此作为 商业银行是否向这些企业发放贷款的依据, 实证发现 该模型具有较好的拟合度, 具有一定的应用价值。王 健、吕德宏（2009） ${ }^{[14]}$ 通过 Credit Metrics 模型度量 商业银行的信用风险对于供应链金融风险的度量具 有一定的借鉴意义。

综上, 供应链金融信用风险的评价体系研究较之 于评价方法的研究更完善一些, 其相关研究成果为本 文的研究提供了良好的思路, 本文针对已有指标体系 信息不充分和评价方法单一的局限, 引入包含百度搜 索指数、股吧综合评分的外部条件因素, 从营运能力、 偿债能力、盈利能力、发展潜力、抵押因素、条件因 素六个方面构建供应链金融信用风险评价体系; 并选 取了不同模式下的跟互联网供应链金融相关的 24 家 上市公司的 2019 年度财务指标数据, 运用结构摘权 -TOPSIS 法对 24 家上市公司的信用风险进行分析与 评价。

\section{2. 供应链金融信用风险评价指标体系构建}

本文依据不同模式下互联网供应链金融企业的特 征, 基于信用 $5 \mathrm{C}$ 理论, 遵循科学性、代表性、客观 性、针对性、实用性等评价指标选取原则, 引入包含 百度搜索指数、股吧综合评分的外部条件因素, 百度 搜索指数反映了该公司被搜索频次, 股吧综合评分为 某一股票信息交流网站对某只股票的综合评价值，从 营运能力、偿债能力、盈利能力、发展潜力、抵押因 素、条件因素六个方面构建了包含 6 个一级指标和 17 个二级指标在内的供应链金融信用风险评价指标 体系，如表一所示:
表 1 信用风险评价指标体系

\begin{tabular}{|c|c|c|}
\hline 目标层 & 一级指标 & 二级指标 \\
\hline \multirow[b]{6}{*}{ 供 } & \multirow{3}{*}{ 营运能力 } & 存货周转率 Z1 \\
\hline & & 应收账款周转率 Z2 \\
\hline & & 总资产周转率 Z3 \\
\hline & \multirow{3}{*}{ 偿债能力 } & 流动比率 Z4 \\
\hline & & 速动比率 Z5 \\
\hline & & 资产负债率 Z6 \\
\hline \multirow{4}{*}{$\begin{array}{l}\text { 应 } \\
\text { 链 } \\
\text { 金 }\end{array}$} & \multirow{4}{*}{ 盈利能力 } & 营业利润 Z7 \\
\hline & & 销售毛利润率 Z8 \\
\hline & & 净资产收益率 Z9 \\
\hline & & 总资产报酬率 Z10 \\
\hline \multirow{7}{*}{$\begin{array}{l}\text { 用 } \\
\text { 风 } \\
\text { 险 }\end{array}$} & \multirow{3}{*}{ 发展潜力 } & 营业利润增长率 Z11 \\
\hline & & 营业收入增长率 Z12 \\
\hline & & 总资产增长率 Z13 \\
\hline & \multirow[t]{2}{*}{ 抵押因素 } & 存货净额 Z14 \\
\hline & & 应收账款 Z15 \\
\hline & \multirow{2}{*}{ 条件因素 } & 百度搜索频次 Z16 \\
\hline & & 股吧综合评分 Z17 \\
\hline
\end{tabular}

\section{3. 评价模型构造}

\section{1 结构熵权法}

结构熵权法是集定量分析、定性分析、主客观赋 值法于一体的评测指标体系权重的新方法。具体步骤 如下:

(1) 搜集意见，形成排序

(2) 对排序进行盲度分析，计算总体认识度。假设共 有 $\mathrm{s}$ 位专家，共有 $\mathrm{s}$ 张调查表，每一张表对应一个指 标集 $T=\left(t_{1}, t_{2}, \ldots, t_{n}\right)$; 指标的初始排序矩阵为 $A\left(A=\left(a_{i j}\right)_{s^{*} n}, i=1,2, \ldots, s ; j=1,2, \ldots, n\right) \quad$, 这里 $a_{i j}$ 是 
第 $i$ 位专家对第 $j$ 个指标 $T_{j}$ 的评价。对上述排序进行熵 函数的转换如下:

$x(h)=-\lambda P n(h) \ln P n(h)$

其中, 令

$$
P n(h)=\frac{m-h}{m-1}, \lambda=\frac{1}{\ln (m-1)}
$$$$
\text { 带入式子（1）, 得到 } u(h)=\frac{\ln (m-h)}{\ln (m-1)}
$$

$h$ 是某个评价指标对应的定性排序数, $m$ 为转换参 数量。令 $m=j+1, j$ 为实际最大顺序号, 将 $a_{i j}$ 代入 式子 (3) 即可以得到隶属度矩阵 $B=\left(b_{i j}\right)_{s^{*} n}$ ，其中 $u\left(a_{i j}\right)=b_{i j}$ 平均认识度为 $b_{j}=\sum_{i=1}^{s} b_{i j} / s$ 表示 $\mathrm{s}$ 位专家对 指标 $u_{j}$ 的一致看法。专家对指标由认知产生的不确定 性称为 “认识盲度” ，记做

$Q_{j}=\frac{\max \left(b_{1 j}, b_{2 j}, \ldots, b_{s j}\right)-b_{j}+\min \left(b_{1 j}, b_{2 j}, \ldots, b_{s j}\right)-b_{j}}{2}$

对于每一个指标，定义 $s$ 位专家关于 $u$ 的总体认 识度为

$x_{j}=b_{j}\left(1-\left|Q_{j}\right|\right)$

由此, 可以得到 $s$ 位专家对指标 $u_{j}$ 的评价向量 $X=\left(x_{1}, x_{2}, \ldots, x_{m}\right)$ 。

(3) 归一化处理

运用结构熵权法算出权重: $\alpha_{j}=\frac{x_{j}}{\sum_{i=1}^{m} x_{j}}$

\section{2 TOPSIS 法}

TOPSIS 法为逼近理想解的排序方法。方法的基 本原理是定义决策问题的最优解和最劣解, 通过检测 待估对象到最优解、最劣解的距离进行评价排序具体 步骤如下:

（1）构造初始决策矩阵

设有 $\mathrm{n}$ 个评价指标, $\mathrm{m}$ 个待估企业 $X_{i j}$ 为第 $\mathrm{i}$ 个 待估企业的第 $\mathrm{j}$ 个指标所对应的数据 $(i=1,2,3 \ldots . ., \mathrm{m} ; j=1,2,3 \ldots, n)$ ，由此构造决策矩阵

$R x$ :

$$
R_{\mathrm{x}}=\left[\begin{array}{ccc}
X_{11} & \ldots & X_{1 n} \\
\ldots & X_{i j} & \ldots \\
X_{m 1} & \ldots & X_{m n}
\end{array}\right]
$$

(2) 归一化矩阵

为了解决数据间规模不同的多属性决策问题, TOPSIS 法对决策矩阵做了归一化处理, 提高了各经 济指标数据可比度, 便于计算分析。通常, 采用如下
公式对矩阵规范化: $X_{i j}^{\prime}=\frac{X_{i j}}{\sqrt{\sum_{i=1}^{m} X_{i j}{ }^{2}}}$ 由此得到, 归一化决
策矩阵 $R_{x}^{\prime}$ :

$$
R_{x}^{\prime}=\left[\begin{array}{ccc}
X_{11} & \ldots & X_{1 n}{ }^{\prime} \\
\ldots & X_{i j}{ }^{\prime} & \ldots \\
X_{m 1} & \ldots & X_{m n}
\end{array}\right]
$$

(3) 构造加权规范化矩阵 $V_{i j}$

$$
V=\left[\begin{array}{ccc}
V_{11} & \ldots & V_{1 n} \\
\ldots & V_{i j} & \ldots \\
V_{m 1} & \cdots & V_{m n}
\end{array}\right]
$$

(4) 确定正负理想解

正理想解 $d_{i}^{-}$由正向指标的最大值或负向指标最 小值组成, 负理想解 $d_{i}^{-}$由正向指标的最小值或负向 指标的最大值组成。

$$
\begin{aligned}
& V^{+}=\left\{\left(\max _{1 \mathrm{ism}} V_{i j}\right)\left|j \in J,\left(\min _{1 \mathrm{ism}} V_{i j}\right)\right| j \in J^{\prime}\right\}=\left\{V_{1}^{+}, \ldots, V_{j}^{+}, \ldots, V_{n}^{+}\right\} \\
& V^{-}=\left\{\left(\min _{1 \leq \mathrm{i} m} V_{i j}\right)\left|j \in J,\left(\max _{1 \leq \mathrm{ism}} V_{i j}\right)\right| j \in J^{\prime}\right\}=\left\{V_{1}^{-}, \ldots, V_{j}^{-}, \ldots, V_{n}^{-}\right\}
\end{aligned}
$$

(5) 计算欧氏距离

正负理想解的确定，各企业信用风险评价指标向量 欧式距离公式为:

$$
\begin{aligned}
& d_{i}^{-}=\sqrt{\sum_{j=1}^{n}\left(V_{i j}-V_{j}^{-}\right)^{2}} \\
& d_{i}^{+}=\sqrt{\sum_{j=1}^{n}\left(V_{i j}-V_{j}^{+}\right)^{2}}
\end{aligned}
$$

(6) 计算贴近度

在计算得出各企业的欧式距离后, 依据相对贴进 度这一指标作为损信用风险的综合评价值。相对贴进 度的计算公式为:

$C_{i}=\frac{d_{i}^{-}}{d_{i}^{+}+d_{i}^{-}}(i=1,2, \ldots, m)$

(7) 对企业信用风险进行排序

根据贴近度的大小，对 24 个互联网供应链金融 下的企业进行排序 $C_{i}$ 值越大, 表明该企业距正理想 解越近, 信用风险越低, 反之越高。

\section{4. 数据选取与实证分析}

\section{1 数据选取}

本文选取了在沪深股市上市的 2019 年度跟互联 网供应链金融相关的 24 家上市公司的指标数据。数 据主要来源于 wind 数据库, 百度搜索指数 (http://index.baidu.com) 和同花顺官方数据。 


\section{2 实证结果}

由指标原始财务数据, 通过结构熵权法求出 17 个指标各自所占的权重, 如表二所示。根据 TOPSIS 法可以得到 24 家上市公司的相对贴近度以及分析排 序, 如表三所示。

表 2 结构熵权法计算下的指标权重

\begin{tabular}{|c|c|c|c|}
\hline 指标 & 权重 & 指标 & 权重 \\
\hline $\mathrm{Z1}$ & 0.072 & $\mathrm{Z} 10$ & 0.059 \\
\hline $\mathrm{Z2}$ & 0.077 & $\mathrm{Z} 11$ & 0.060 \\
\hline $\mathrm{Z3}$ & 0.066 & $\mathrm{Z} 12$ & 0.054 \\
\hline $\mathrm{Z4}$ & 0.079 & $\mathrm{Z} 13$ & 0.041 \\
\hline $\mathrm{Z5}$ & 0.064 & $\mathrm{Z} 14$ & 0.044 \\
\hline $\mathrm{Z6}$ & 0.069 & $\mathrm{Z} 15$ & 0.053 \\
\hline $\mathrm{Z7}$ & 0.068 & $\mathrm{Z} 16$ & 0.044 \\
\hline $\mathrm{Z8}$ & 0.060 & $\mathrm{Z} 17$ & 0.038 \\
\hline $\mathrm{Z9}$ & 0.052 & & \\
\hline
\end{tabular}

表 324 家互联网供应链企业信用风险评价结果

\begin{tabular}{|c|c|c|}
\hline 企业名称 & $\mathrm{Ci}$ & 排名 \\
\hline *ST 欧浦 $(002711)$ & 0.425662014 & 7 \\
\hline 上海钢联 (300226) & 0.505661768 & 2 \\
\hline 东方集团 (600811) & 0.386623677 & 18 \\
\hline 久其软件 (002279) & 0.400322507 & 12 \\
\hline 云南城投 (600239) & 0.260806246 & 22 \\
\hline 华软科技 (002453) & 0.298015526 & 21 \\
\hline 南山铝业 (600219) & 0.454288389 & 4 \\
\hline 合兴包装 (002228) & 0.397823461 & 14 \\
\hline 奥马电器 (002668) & 0.394440197 & 13 \\
\hline 宁波东力 (002164) & 0.366546248 & 20 \\
\hline 密尔克卫 (603713) & 0.436763859 & 3 \\
\hline 怡亚通 (002183) & 0.417054539 & 9 \\
\hline 摩恩电气 (002451) & 0.372379256 & 19 \\
\hline 新能泰山 (000720) & 0.428624134 & 8 \\
\hline 易见股份 (600093) & 0.538962114 & 1 \\
\hline 汉宇集团 (300403) & 0.403803368 & 10 \\
\hline 派生科技 (300176) & 0.273299906 & 23 \\
\hline 浙江东方 (600120) & 0.437563702 & 5 \\
\hline
\end{tabular}

\begin{tabular}{|c|c|c|}
\hline 海联讯 (300277) & 0.386515946 & 15 \\
\hline 漳泽电力 (000767) & 0.386566146 & 16 \\
\hline 瑞丰高材 (300243) & 0.388592466 & 17 \\
\hline 瑞茂通 (600180) & 0.410842421 & 11 \\
\hline 联络互动 $(002280)$ & 0.199134114 & 24 \\
\hline 生意宝 $(002095)$ & 0.421684201 & 6 \\
\hline
\end{tabular}

TOPSIS 法得到的相对贴近度作为 24 家供应链 企业的信用风险综合评价值。

从得到的排序结果来看, 诸如德威新材、摩恩电 气等一些材料制造业的企业由于疫情冲击导致存货 积压、资金流动受限、经营业绩不佳从而易产生信用 风险; 提供数据采集与分析的互联网高科技企业如久 其软件、新能泰山等由于研发需要大量的资金, 致使 资产负债率过高, 并且这类企业的投入与产出不一定 成正比, 产品的生产周期较长, 风险适中; 派生科技、 华软科技等互联网供应链金融投资与借贷平台虽然 资本流动性较好但发展不稳定往往伴随着较高的风 险。

\section{5. 研究结论及展望}

\section{1 研究结论}

本文选取了 24 家互联网供应链金融下的上市企 业，搜集了这些企业的 2019 年度的财务指标，利用 结构熵权-TOPSIS 法进行实证分析, 得出了以下结 论: 第一, 反映企业偿债能力的流动比率和反应营运 能力的应收账款周转率、存货周转率占较大的比重。 这几个指标对于中小企业的信用风险影响为正, 这些 比率越高则信用风险越低。第二, 就中小企业的风险 排序而言,一些材料供应电商平台受宏观经济的影响 易产生存货积压、资金流动受限、经营业绩不佳的问 题从而易产生信用风险; 提供数据采集与分析的互联 网高科技企业由于研发需要大量的资金, 致使资产负 债率过高, 并且这类企业的投入与产出不一定成正 比，产品的生产周期较长; 互联网供应链金融投资与 借贷平台虽然资本流动性较好但发展不稳定往往伴 随着较高的风险。因此, 金融机构在对中小企业进行 贷款融资时一定要构建完善的风险评估体系来降低 
可能出现的损失。

\section{致谢}

感谢贵州省农村合作制经济项目《数字普惠金融 对乡村振兴的影响研究——以贵州省 10 个乡村振兴 示范县为例》的资助。

\section{参考文献}

[1]许贵义. 供应链金融下中小企业信用风险评价指 标体系构建研究 [D]. 福建师范大学, 2016.

[2] 肖瑾. 浅析供应链金融中信用风险的评价体系构 建 $[\mathrm{J}]$. 经贸实践, 2018 (19): 125 .

[3]刘兢轶, 王或婧, 王静思. 供应链金融模式下中小 企业信用风险评价体系构建 $[\mathrm{J}]$. 金融发展研 究, 2019 (11) :63-67.

[4]袁双龙. 供应链金融中信用风险的评价体系构建 研究 [J]. 财会学习, 2019 (34) : 182-183.

[5]熊莉. 供应链金融信用风险评价体系构建研究 [J]. 财会学习, 2019 (26) :202-204.

[6] 韩琴. 供应链金融视角下的中小企业信用风险评 价指标体系构建 [J]. 时代金 融, $2019(09): 171-172$.

[7]张俊材, 徐超毅. 论钢铁行业供应链金融信用风险 评价体系 $[\mathrm{J}]$. 盐城工学院学报 (社会科学 版), 2019, 32 (04) : 48-51.

[8] 匡海波, 杜浩, 丰吴月. 供应链金融下中小企业信 用风险指标体系构建 $[\mathrm{J}]$. 科研管 理, 2020, 41 (04):209-219.

[9] Bin Zhu, Zeshui Xu.Overview on the Developments and Applications of Hesitant Fuzzy Sets: An Uncertain Decision Making Tool[J].Journal of Risk Analysis and Crisis Response, 2016, 2 (06) :67-75.

[10]李杰辉, 陈珊珊. 基于 Logistic 模型的供应链金融
信用风险实证研究——以房地产上市公司为例 [J]. 金融理论与教学, $2020(04): 21-29$

[11] 赵欢. 商业银行线上供应链金融信用风险评价 研究 [D]. 西安理工大学, 2020.

[12]邓伟. 基于 KMV 模型的信用风险度量研究一一以 制造业上市公司为例 $[\mathrm{J}]$. 现代营销 (信息 版), 2020 (07) : 18-19.

[13] 张天宇. 基于 KMV 模型的上市中小企业信用风险 评估研究 [J]. 科技经济导刊, 2020, 28 (16) :229.

[14]王健, 吕德宏. 基于 Credit Metrics 模型的我国商 业银行贷款信用风险度量分析 $[\mathrm{J}]$. 商场现代 化, 2009 (05) : 355. 